\title{
Tiyosemikarbazit ve bis-1,2,4-triazol Türevlerinin Antikanser, Apoptotik ve Antibakteriyal Etkileri
}

\author{
Gülden $\mathrm{KOÇAK}^{1 *}$, Emine AKDEMİR ${ }^{2}$ \\ ${ }^{1}$ Bingöl Üniversitesi, Moleküler Biyoloji ve Genetik Bölümü, Bingöl \\ ${ }^{2}$ Bingöl Üniversitesi, Fen Bilimleri Enstitüsü, Biyoloji Anabilim Dall, Bingöl \\ (ORCID: 0000-0002-3890-0579) (ORCID: 0000-0003-1905-8344)
}

\begin{abstract}
Öz
Bu çalışmada, çıkış maddesi piridin-2,5-dikarbohidrazin (2) ile tiyosemikarbazit türevleri [2,2'-(piridin-2,5diildikarbonil-bis(N-etilhidrazinkarbotiyoamit) (3B) ve 2,2'-(piridin-2,5-diildikarbonil)-bis(N-(pmetoksifenil)hidrazinkarbotiyoamit (3C)] ve bu bileşiklerin halkalaşmasından oluşan bis-1,2,4-triazol türevlerinin [5,5-piridin-2,5-diilbis(4-etil-4H-1,2,4-triazol-3-tiyol) (4B) ve 5,5'-piridin-2,5diilbis[4-(4-metoksifenil)-4H1,2,4-triazol-3-tiyol)] (4C)] in vitro ortamda prostat kanser hücre hattı (PC-3) üzerindeki antikanser ve apoptotik etkileri ile bazı gram pozitif ve gram negatif bakteriler üzerindeki antibakteriyel etkileri belirlenmiş̧ir. Antikanser etki sonuçlarına göre tüm maddelerin artan konsantrasyonlara bağlı olarak canlı kanser hücre sayısında azalma tespit edilmiştir. Tüm uygulanan maddelerde en yüksek sitotoksik etkinin $500 \mu \mathrm{M}$ konsantrasyonda olduğu belirlenmiştir. Tüm maddelerin apoptozu tetiklediği belirlenmiş olup apoptotik indeks oranlarına bakıldığında en düşük apoptotik indeks oranı 4B maddesi uygulandığında, en yüksek apoptotik indeks oranı ise 3C maddesi uygulandığında tespit edilmiştir. Antibakteriyel çalışmada tüm bileşiklerin gram pozitif bakteriler üzerinde gram negatiflere nazaran daha fazla etkili olduğu görülmüştür.
\end{abstract}

Anahtar Kelimeler: PC-3, tiyosemikarbazit, triazol, antikanser, apoptotik etki, antibakteriyel etki.

\section{Anticancer, Apoptotic and Antibacterial, Effects of Thiosemicarbazid and bis-1,2,4-Triazole Derivatives}

\begin{abstract}
In this study in vitro anticancer and apoptotic activities on the prostate cell line (PC-3) and antibacterial effects on some gram positive and gram negative bacteria of pyridine-2,5-dicarbohydrazine and synthesized thiosemicarbazide derivatives [2,2' -(pyridine-2,5-diyldicarbonyl)-bis(N-ethylhydrazinecarbothioamide) (3B)and [2,2'-(pyridine-2,5-diyldicarbonyl)-bis[N-(p-methoxyphenyl)hydrazinecarbothioamide] (3C)] and bis-1,2,4triazole-3-thiol derivatives [5,5'-pyridine-2,5-diylbis(4-ethyl-4H-1,2,4-triazole3-thiol) (4B) and 5,5'-pyridine-2,5diylbis(4-(4-methoxy-phenyl)-4H1,2,4-triazole-3-thiol) (4C)] were determined. According to the results of cytotoxic studies cell numbers decreased by the concentration increase of all compounds. The maximum cytotoxic effects were found on $500 \mu \mathrm{M}$ concentration. As a result of apoptotic activity it is found out that all of the compounds triggered the apoptosis and the lowest index was on $4 \mathrm{~B}$ and the highest index was on $3 \mathrm{C}$ compounds. Antibacterial tests showed that all compounds used in this study were more effective on gram positive bacteria then gram negative bacteria.
\end{abstract}

Keywords: PC-3, thiosemicarbazid, triazole, anticancer, apoptotic effects, antibacterial effects.

\section{Giriş}

Prostat kanseri dünya genelinde ve ülkemizde erkeklerde en sık görülen kanser tiplerinden birisidir. 2018 yılı küresel kanser istatistik verilerine göre prostat kanseri dünyada erkekler arasında en sık ikinci görülen kanser tipi iken kansere bağlı ölümlerde beşinci sırada bulunmaktadır [1]. Endojen risk faktörleri arasında aile geçmişi, hormonlar, rrk, yaş ve oksidatif stres, eksojen risk faktörleri arasında ise

"Sorumlu yazar: gkocak@bingol.edu.tr

Geliş Tarihi: 23.01.2020, Kabul Tarihi: 28.04.2020 
diyet, çevresel ajanlar ve meslek seçimi sayılabilir [2].Yaşa bağlı olarak görülme sıklığı değişmekte olup 0-39 yaş erkeklerde rastlanma olasıllığ $\% 0.01,40-59$ yaş erkeklerde $\% 2.58$ ve $60-79$ yaş erkeklerde $\% 14.7$ olarak tespit edilmiştir [3].

Günümüzde, polifonksiyonel ve heteroatom ihtiva eden halkalı bileşiklerinden antioksidant, antimikrobiyal ve antikanser özelliklerine sahip olanların sentezi önemli olup; biyokimya, tıp ve eczacılık gibi çok önemli disiplinlerde kullanım alanı bulabilmektedir $[4,5]$. Triazoller eşsiz yapı ve özelliklerinden dolayı tıp ve tarımsal kimya gibi birçok bilim dalının dikkatini çekmektedir [6]. Son yıllarda 1,2,4-triazollerin heterosiklik türevleri üzerindeki çalışmalar sentetik ve biyolojik öneminden dolayı giderek artmaktadır [4]. Bugüne kadar yapılan çeşitli çalışmalarda antifungal, antikolsüvan, antitüberküloz, antioksidan, anti-enflamatuar, antikanser ve antimikrobiyal aktivitelerinin olduğu rapor edilmiştir [7-12] Aynı zamanda korozyon önleyici [13], pestisit [14], boya [15], asit baz indikatörü [16] ve endüstriyel kimyasallar [17] olarak diğer kullanım alanları da mevcuttur.

Antimikrobiyal ilaç olarak sıkça kullanılan azol grubu triazoller arasında flukonazol, itrakonazol, terkonazol, posakonazol ve vorikonazol sayılabilir. Bununla beraber diğer triazol ilaçlar arasında sayılabilecekler şu şekildedir; vorozole, letrozol ve anastrozol kanser tedavisinde non-steroidal ilaçlar olarak kullanılmaktadırlar; ribavirin bir nükleosit olmaya ters transkriptaz inhibitörüdür ve çok etkili bir antiviral ajan olup DNA ve RNA virüslerinde çok ciddi etkiler gösterir; rizatriptan, antimigren ajanıdır, trazodon antidepresan olarak trapidil hipotansif; benatradin, diüretik ve etoperidon antideprasan olarak kullanılmaktadır $[4,18]$.

İlk defa bu çalışma ile piridin-2,5-dikarbohidrazin çıkış bileşiği (2) ile tiyosemikarbazit türevleri [2,2'-(piridin-2,5-diildikarbonil-bis(N-etilhidrazinkarbotiyoamit) (3B) ve 2,2'-(piridin-2,5diildikarbonil)bis(N-(p-metoksifenil)hidrazinkarbotiyoamit (3C)] ve bu bileşiklerin halkalaşmasında oluşan bis-1,2,4-triazol türevlerinin [5,5-piridin-2,5-diilbis(4-etil-4H-1,2,4-triazol-3-tiyol) (4B) ve 5,5'piridin-2,5diilbis[4-(4-metoksifenil)-4H-1,2,4-triazol-3-tiyol)] (4C) ] in vitro ortamda prostat kanser hücre hattı PC-3 üzerindeki antikanser ve apoptotik aktivitesi ile bazı gram pozitif ve gram negatif bakteriler üzerindeki antibakteriyel etkilerinin belirlenmesi hedeflenmiştir.

\section{Materyal ve Metod}

\subsection{PC-3 hücre kültürüi}

PC-3 hücre kültürü büyüme ortamı hazırlamak için 89 mL RPMI 1640 (\%1 L-glutamin, \%1 sodyum pirüvat ve sodyum bikarbonat içeren), $10 \mathrm{~mL}$ fetal calf serumu ve $1 \mathrm{~mL}$ penisillin-streptomisin [penisilin $(100 \mathrm{U} / \mathrm{mL})$, streptomisin $(100 \mu \mathrm{g} / \mathrm{mL})]$ medium kabında karıştırıldı. Her kullanımdan önce taze hazırlandı.

\subsection{Bakteri Büyüme Ortamı}

Antimikrobiyal testte kullanılacak bakteri kültürlerini hazırlamak için, 34 gr Müller Hinton agar distile su ile $1000 \mathrm{~mL}$ 'ye tamamland. Magnetik karıştırıcı ile homojen hale getirildi. Daha sonra otoklavda $120^{\circ} \mathrm{C}$ 'de $15 \mathrm{dk}$ boyunca steril hale getirileren besiyeri steril petri kaplarına döküldü. Steril ortamda soğumaları beklendi ve $+4^{\circ} \mathrm{C}$ 'de saklandı.

\subsection{Hücre Hatları}

Hazırlanan maddelerin in-vitro antikanser aktivite potansiyellerini belirlemek amaciyla deneylerimizde prostat kanser hücre hattı olan PC-3 kullanıldı. PC-3 hücre hatları ODTÜ Biyoloji bölümünden temin edilmiştir. Bingöl Üniversitesi Merkezi Araştırma Laboratuvar Hücre Kültürü Laboratuvarında sıvı nitrojende saklanmaktadır.

\subsection{Tiyosemikarbazit ve 1,2,4-triazol türevleri}

Bu çalışmada kullanılan tiyosemikarbazit ve 1,2,4-triazol türevleri, Bingöl Üniversitesi Kimya Bölümü Öğretim Üyesi Prof. Dr. Ahmet Çetin tarafından sentez edilmiştir. 2 numaralı çıkış bileşiğinin hidrazit uçları etil izotiyosiyanat grubu ile türevlendirilerek 3B bileşiği elde edilmiştir. Sonra bileşiğin her iki 
hidrazit ucuda p-metilizotiyosiyanat grubu ile türevlendirilerek 3C bileşiği elde edilmiştir. Oluşan bu alkil (3B) ve ariltiyosinat (3C) grubu bileşikleri hidrolize edilerek 1,2,4-triazol-3-tiyol gruplarına halkalaşmaları sonucu 3B bileşiği 4B'ye, 3C bileşiği de 4C'ye dönüşmüştür. Sonuç olarak 2 numaralı piridin-2,5-dikarbahidrazit bileşiğinin fonksiyonel uçları alkil ve aril grupları ile modifiye edilmiştir. Sonrasında bu modifiye bileşiklerin 1,2,-4 triazol halkasına dönüşümleri sağlanmıştır $[5,19]$.

\subsection{Bakteri Suşları}

Bu çalışmada kullanılan bakteri suşları (Bacillus subtilis ATCC 6337, Brevibacillus brevis, Bacillus megaterium DSM 32, Bacillus subtilis IM 622, Bacillus cereus EMC 19, Staphylococcus aureus 6538P, Listeria monocytogenes NCTC 5348, Salmonella typhimurium NRRLE 4413, Pseudomanas fluorescens, Enterobacter aerogenes CCM 2531, Klebsiella pneumoniae EMCS, Escherichia coli ATCC 25922, Proteus vulgaris FMC II, Proteus vulgaris Salmonella enterica ATTC 13311) Bingöl Üniversitesi Moleküler Biyoloji ve Genetik Bölümü Doç. Dr. Fethi Ahmet Özdemir'den temin edilmiş̧ir. Bakteri suşları Bingöl Üniversitesi Moleküler Biyoloji ve Genetik Bölümü Laboratuvarında saklanmaktadır.

\subsection{Madde Ekstraktlarının PC-3 İçeren Plaklara Ekilmesi}

PC-3 hücreleri $\% 5 \mathrm{CO}_{2}{ }^{\prime} l i$ inkübatörde $37^{\circ} \mathrm{C}^{\prime}$ de $25 \mathrm{~cm}^{2}$ lik hücre kültür flasklarında yeterli sayıda çoğaltıld1, sonra her flasktan eski büyüme ortamı $5 \mathrm{~mL}$ ' lik serolojik pipet kullanılarak otomatik pipetle tamamen çekilerek uzaklaştırıldı. Ölü hücreleri flasktan uzaklaştırabilmek için her flaska $1 \mathrm{~mL}$ PBS eklendi ve hücrelerin PBS ile tamamen yıkanması sağlandı. Eklenen PBS tekrar çekilerek uzaklaştırıldı. Hücreleri kaldırmak için her flaska $1 \mathrm{~mL}$ tripsin-EDTA enzimi eklenerek $\% 5 \mathrm{CO}_{2}$ atmosferli inkübatörde $3 \mathrm{dk}$ inkübe edildi. Daha sonra her flaska $1 \mathrm{~mL}$ RPMI-1640 büyüme ortamı eklenerek tripsin enziminin etkisi giderildi. Her flaskdan tamamı otomatik pipetle çekilerek $15 \mathrm{~mL}$ falkon tüpüne aktarıldı. Falkon tüpteki hücreler 500 rpm'de 2 dakika santrifüj edildikten sonra süpernatant kısmı uzaklaştırıldı. Hücrelerin üzerine $1 \mathrm{~mL}$ RPMI 1640 büyüme ortamı eklendi ve hücrelerin büyüme ortamıyla iyice karışması sağlandı. Hücre sayımı için falkon tüpten mikropipet kullanılarak $10 \mu \mathrm{L}$ örnek alındı ve ependorf tüpe konulup üzerine $10 \mu \mathrm{L}$ tripan blue eklendi ve iyice karışması sağlandı.

\subsection{WST-1 Hücre Canlılık Testi}

Hücre canlılık testi WST-1 hücre canlılık kiti protokolüne göre yapıldı. Hemositometre ile yaşayan hücreler sayıldı. 96 kuyucuklu plakalara hücre ekimi yapılacağ 1 için her kuyucukta yaklaşık $2 \times 10^{4}$ hücre olacak şekilde kullanıldı. Hücre ve büyüme ortamı miktarı hesaplandı. Büyüme ortamı eklenerek $15 \mathrm{~mL}$ falkon tüp içinde hazırlandı. Her kuyucuğa $100 \mu \mathrm{L}$ hücre konduktan sonra hücreler $\% 5 \mathrm{CO}_{2}{ }^{\prime} l i$ inkübatörde çoğalmaları için 24 saat inkübe edildi. Örneklerden, 10, 25, 50, 100, 250, $500 \mu \mathrm{M}$ tartıldı ve $1.5 \mathrm{~mL}$ ependorf tüp içerisinde $20 \mathrm{~mL}$ DMSO içinde çözünerek istenen konsantrasyon hazırland. Üzerine $1000 \mu \mathrm{M}$ lara tamamlayacak kadar RPMI 1640 besiyeri eklendi ve $1000 \mu \mathrm{M}$ stok çözelti hazırlandı. Hazırlanan konsantrasyon sonikatörle iyice karıştırıldı, karışan bu maddelerin besiyeri içerisinde homejen olarak dağılması sağlandı. Tüm kuyucuklardaki besiyeri hücrelere zarar vermeyecek şekilde mikro pipetle çekildi ve ortamdan uzaklaştırıldı. PC-3 hücreleri, 5-100 $\mu \mathrm{g} / \mathrm{mL}$ olacak konsantrasyonlarda madde ekstraktına sahip olan besiyeri ile $\% 5 \mathrm{CO}_{2} l i$ inkübatörde 24 saat inkübe edildi ve örneklerin hücrelere etki etmesi beklendi. Kontrol grubu olarak kuyucuklara sadece $100 \mu \mathrm{M}$ RPMI 1640 besiyeri ilave edildi. 24 saat inkübasyon sonunda her bir kuyucuğa $15 \mu \mathrm{L}$ WST-1 maddesi eklendi. Hücreler $\% 5 \mathrm{CO}_{2}$ li inkübatörde $37^{\circ} \mathrm{C}$ 'de 4 saat inkübe edildi. 4 saat inkübasyondan sonra 96 gözlü plak ELISA reader cihazına yerleştirildi ve her bir kuyucuğun 450-630 nm deki absorbans değerleri alındı ve kaydedildi.

\subsection{Apoptaz Kaspaz 3 Assay Kit[C]}

Hücreler kültür ortamında çoğaltıldı. Üzerine $500 \mu \mathrm{M}$ lik konsantrasyonlarda hazırlanan 2, 3B, 3C, 4B ve 4C maddelerinden her bir kuyucuğa $100 \mu \mathrm{M}$ eklendi. 24 saat inkübe edildi. $2 \mathrm{X}$ reaksiyon bufferden $50 \mu \mathrm{L}$ alındı. Toplamda $750 \mu \mathrm{L} 2 \mathrm{X}$ bufferdan 7,5 $\mu \mathrm{L}$ DDT den alındı ve karıştırıldı. Her bir kuyucuğa 
$50 \mu \mathrm{L}$ Cell Lysis bufferdan konuldu. Hücreler 10 dakika boyunca buz üzerinde inkübe edildi. Her bir örneği mikrosantrifüjde [10.000Xg] 1 dakika santrifüj edildi. Süpernatantı alındı ve direk buza konuldu. Her bir örnekten $50 \mu \mathrm{L}$ alındı ve üzerine $50 \mu \mathrm{L} 2 \mathrm{X}$ reaksiyon bufferdan ve $5 \mu \mathrm{L}$ DEVP PNA' dan konuldu. $37^{\circ} \mathrm{C}$ 'de $1-2$ saat bekletildi. $400-405 \mathrm{~nm}$ deki absorbans değerleri ölçüldü.

\subsection{Antimikrobiyal Etkinin İncelenmesi}

Çalışmada maddelerin antimikrobiyal etkinlikleri disk difüzyon yöntemi kullanılarak belirlendi [20]. Bir gece önceden sıvı besi ortamında inkübasyona bırakılan bakteri kültürlerinden steril ve tek kullanımlık petriler içerisine McFarland standardına göre ayarlanan $10^{6}$ hücre $/ \mathrm{mL}$ bakteri süspansiyonu bırakıldı ve 15 mL'lik Müeller Hinton Agar üzerine ekildi. Drigalski çubuğu ile iyice yayıldı. DMSO içinde çözünerek hazırlanan $1000 \mu \mathrm{M}$ lik 2, 3B, 3C, 4B ve 4C maddelerinden $20 \mu \mathrm{L}$ madde alınarak disklere emdirildi. Diskler steril pens ile besiyerine yerleştirildi. 1 saat $+4^{\circ} \mathrm{C}$ 'deki buzdolabında bekletildi. Daha sonra $37^{\circ} \mathrm{C}$ 'lik inkübatörde 24 saat inkübe edildi. Zon çapları ölçüldü [21]. Sonuçlar kaydedildi. Her deney 3 set halinde kontrol örnekle birlikte tekrarland.

\subsection{0. İstatistiksel Analizler}

Tüm verilerin istatiksel analizi Graphpad Prism 5.0 programı Student's two-tailed t-testine göre yapıldı. Tüm sonuçlar ortalama ve \pm standart sapma olarak verildi ve $\% 95$ güven aralığında 0,05 'in altındaki $p$ değerleri, istatiksel olarak anlamlı kabul edildi.

\section{Bulgular ve Tartışma}

\subsection{Antikanser Çalışmaları}

Çalışmamızda tiyosemikarbazit ve 1,2,4-triazol türevlerinin ön denemeler sonucunda belirlenen konsantrasyon değerlerine göre PC-3 hücre kültürlerinde WST-1 yöntemi kullanılarak sitotoksik aktivite değerleri ortaya konulmuştur. Sitotoksik etkileri araştırılan maddelerin farklı konsantrasyonlarının 24 saatlik inkübasyon sonrası değerleri ölçülmüştür. 2 ve 3B maddelerinde artan konsantrasyonuna bağlı olarak hücre sayısının $10 \mu \mathrm{M}, 25 \mu \mathrm{M}, 50 \mu \mathrm{M}, 100 \mu \mathrm{M}$ konsatrasyonlarda kontrole yakın olduğu görülmüştür (Şekil 1, Şekil 2). $250 \mu \mathrm{M}$ de hücre sayısında azalma görülmekle beraber en yüksek sitotoksik etkinin $500 \mu \mathrm{M}$ konsantrasyonda olduğu belirlenmiştir. 3C, 4B ve 4C maddelerinin artan konsantrasyonuna bağlı olarak canlı kanser hücre sayısının giderek azaldığ görülmüştür. En yüksek sitotoksik etkinin $500 \mu \mathrm{M}$ konsantrasyonda olduğu belirlenmiştir (Şekil 3, Şekil 4, Şekil 5).

Triazol ilaçlar günümüzde çeşitli hastalıkların tedavisinde kullanılmaktadır. Bunlardan bazıları; vorozole, letrozol ve anastrozol kanser tedavisinde non-steroidal ilaçlar olarak kullanılmaktadırlar [4]. 4-fluoro-3-phenoxyphenyl ve 2,4-dichloro-5-fluorophenyl içeren 1,2,4- triazol[3,4-b]thiadiazol ve 1,3,4-oxadiazol türevlerinden bazılarının, lösemi, kolon kanseri, akciğer kanseri, renal kanser, prostat kanseri ve göğüs kanseri hücre hatları üzerinde oldukça yüksek antikanser özellikleri olduğu rapor edilmiştir [22]. 1,2,4,-triazollerin türevlerinin özellikle lösemi, yumurtalık ve renal kanser hücre hatları üzerindeki etkilerine olduğu saptanmıştır [23]. Başka bir araştırmada bu tür türevlerden bazılarının MCF7, NCI-H460 ve CNS (SF-268) hücreleri üzerindeki antikanser özellikleri olduğu belirtilmiştir [24]. Yine, bazı 1,2,4- triazol türevlerinin antikanser özellikleri kolon adenokarsinoma hücre hattı (LS180) üzerinde çalışılmış ve olumlu sonuçlar alınmıştır [25].

Bulut ve diğerleri [5] sentezledikleri 1,2,4-triazol (4B ve 4C) ve tiyosemikarbazit (3B ve 3C) maddelerinin biyolojik aktivite çalışmalarında, bileşiklerin başlangıç maddelerine nazaran daha yüksek antioksidan aktivite gösterdiği ve yine tiyosemikarbazit bileşiklerin yüksek indirgeme kapasiteleri olduğunu tespit etmişlerdir. Bu çalışmada ise tüm maddelerin PC-3 hücre hattı üzerinde WST-1 metodu ile sitotoksik etki gösterdiği tespit edilmiş ve uygulanan maddelerin konsantrasyonları arttıkça sitotoksik etkilerinin paralellik gösterdiği gözlemlenmiştir. 


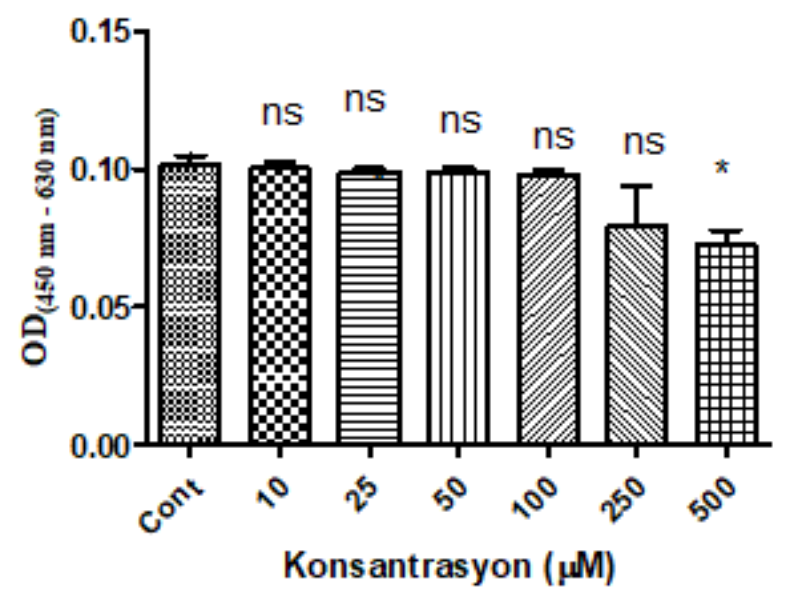

Şekil 1. PC-3 hücre hattında farklı konsantrasyonlardaki 2 maddesinin sitotoksik değerleri. Tüm veriler üç deneyin ortalaması ve \pm SEM olarak ifade edildi. Kontrole karşı; ${ }^{*} \mathrm{P}<0,05,{ }^{\text {ns }} \mathrm{P}>0,05$ (Student's two-tailed ttest)

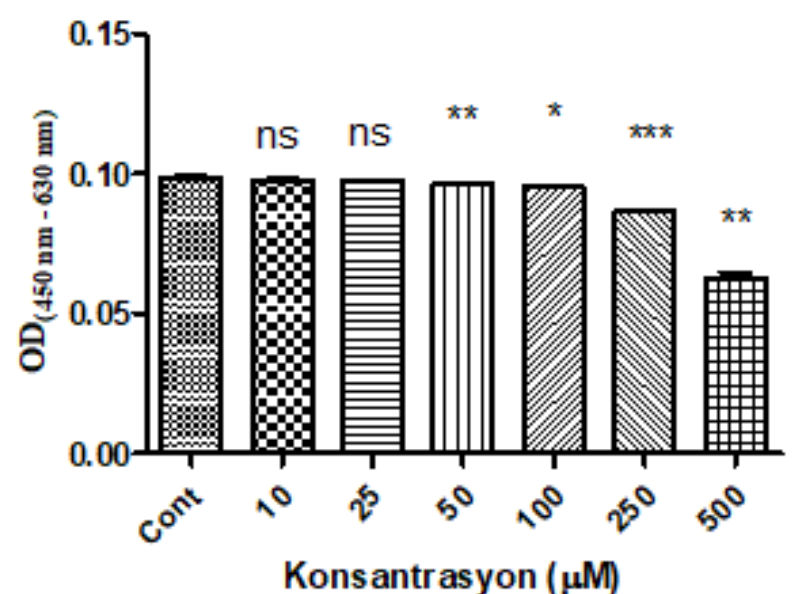

Şekil 2. PC-3 hücre hattında farklı konsantrasyonlardaki 3B maddesinin sitotoksik değerleri. Tüm veriler üç deneyin ortalaması ve \pm SEM olarak ifade edildi. Kontrole karşı; *** $\mathrm{P}<0,001,{ }^{*} * \mathrm{P}<0,01,{ }^{*} \mathrm{P}<0,05,{ }^{\mathrm{ns}} \mathrm{P}>0,05$ (Student's two-tailed t-test)

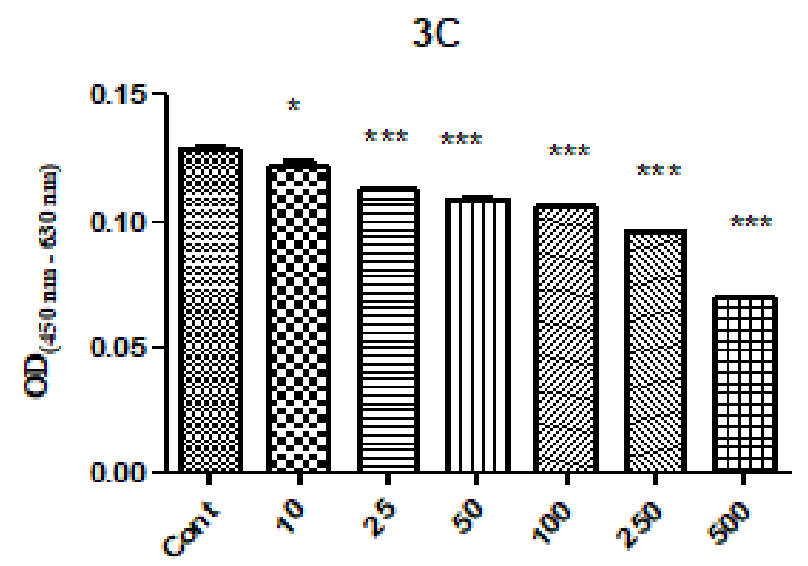

Şekil 3. PC-3 hücre hattında farklı konsantrasyonlardaki 3C maddesinin sitotoksik değerleri. Tüm veriler üç deneyin ortalaması ve \pm SEM olarak ifade edildi. Kontrole karşı; *** $\mathrm{P}<0,001, * \mathrm{P}<0,05,{ }^{\mathrm{ns}} \mathrm{P}>0,05$ (Student's two-tailed t-test) 


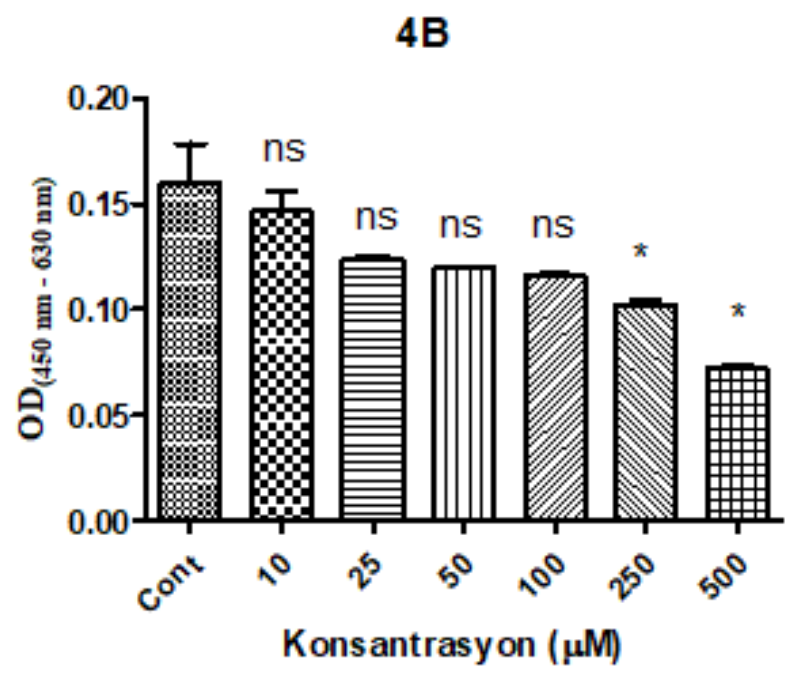

Şekil 4. PC-3 hücre hattında farklı konsantrasyonlardaki 4B maddesinin sitotoksik değerleri. Tüm veriler üç deneyin ortalaması ve \pm SEM olarak ifade edildi. Kontrole karşı; * $\mathrm{P}<0,05$, ${ }^{\mathrm{ns}} \mathrm{P}>0,05$ (Student's two-tailed ttest)

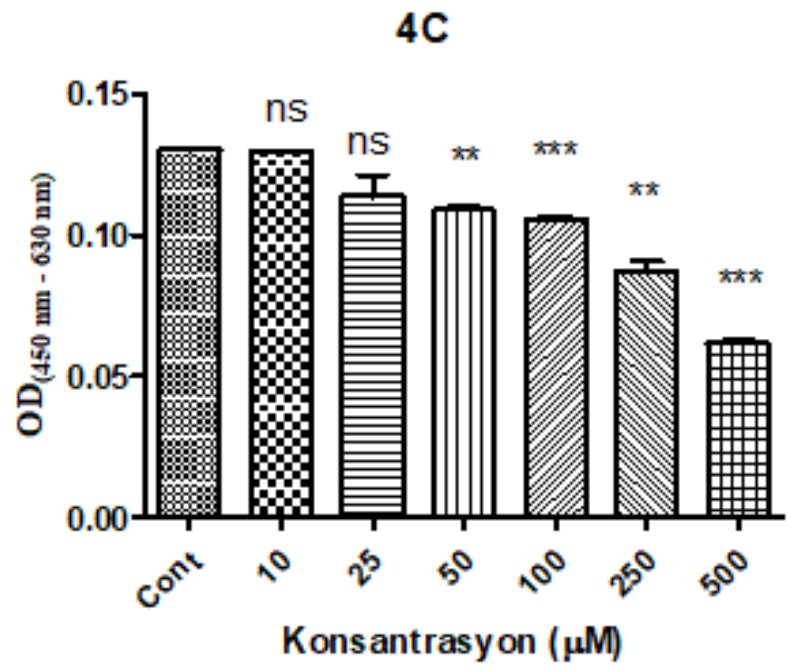

Şekil 5. PC-3 hücre hattında farklı konsantrasyonlardaki 4C maddesinin sitotoksik değerinin belirlenmesi. Tüm veriler üç deneyin ortalaması ve \pm SEM olarak ifade edildi. Kontrole karşı; *** $\mathrm{P}<0,001, * * \mathrm{P}<0,01,{ }^{\text {ns }} \mathrm{P}>0,05$ (Student's two-tailed t-test)

\subsection{Apoptoz-Kaspaz-3 Analizi}

Kaspazlar olarak adlandırılan proteinler, programlanmış hücre ölümünün (apoptoz) en önemli kritik anahtarıdır. Kaspazlar arasında, kaspaz-3, apoptozda birçok önemli hücresel proteinin özel bölgelerinden parçalanmasını katalizleyen ve böylelikle hücresel ölümü aktive eden bir ölüm proteazıdır. Kaspaz-3 bazı tipik apoptoz belirteçleri için de gereklidir ve incelenen tüm hücre tiplerinde apoptotik kromatin yoğunlaşması ve DNA fragmantasyonu için vazgeçilmezdir. Bu nedenle kaspaz-3, hücrenin sökülmesi ve apoptotik cisimlerin oluşumu ile bağlantılı bazı işlemler için şarttır [26].

Bu çalışmada PC-3 hücrelerine uygulanan ve sitotoksit etkisi daha önceden tespit edilen tiyosemikarbazit ve 1,2,4-triazol türevlerinin $500 \mu \mathrm{M}$ 'lk konsantrasyonları ile oluşan kaspaz-3 miktarları kolorimetrik yöntemler ile ölçülmüş ve sonuçlar apoptotik indeks oranlarına göre değerlendirilmiştir. Buna göre Şekil 6'da görüldüğü üzere 2, 3B, 3C, 4B ve 4C maddeleri arasında apoptotik indeks oranı 4B maddesi uygulandığında en düşük, 3C maddesi uygulandığında ise en yüksek değer aldığı tespit edilmiştir. 


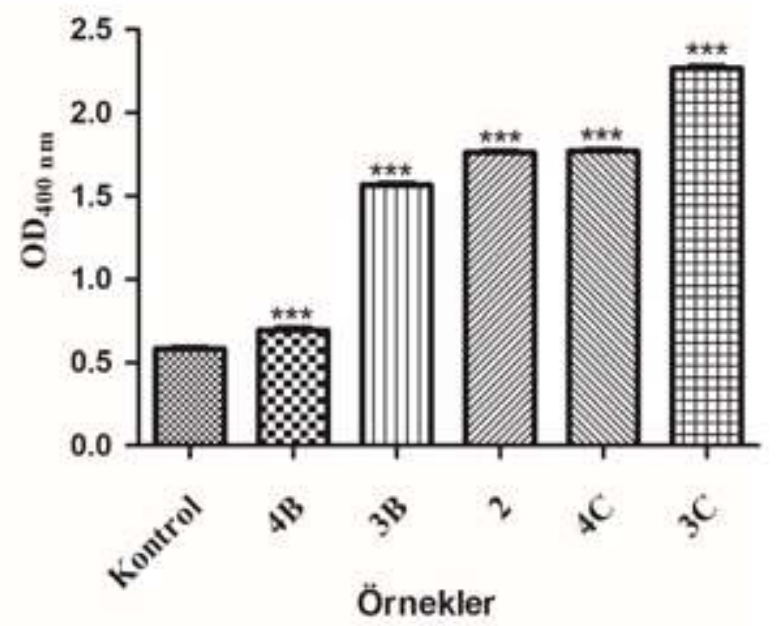

Şekil 6. PC-3 hücre hattında 4B, 4C, 3B ve 3C maddelerinin apoptotik etkilerinin belirlenmesi. Tüm veriler üç deneyin ortalaması ve \pm SEM olarak ifade edildi. Kontrole karşı; *** $\mathrm{P}<0,001$, (Student's two-tailed t-test)

\subsection{Antimikrobiyal Etkinin İncelenmesi}

Antimikrobiyal etki çalışmalarının sonuçları Tablo 1'de gösterilmektedir. Buna göre, 2 numaralı madde uygulandığında en fazla etkinin Listeria monocytogenes NCTC 5348'de (zon çap1 9 mm) görüldüğ̈̈; en az etkinin ise Pseudomonas aeruginosa DSM 50070 ve Proteus vulgaris FMC II (zon çap $1 \mathrm{~mm}$ ) suşlarında görüldüğü tespit edilmiş̧ir. Proteus vulgaris test suşunda ise herhangi bir antimikrobiyal etki kaydedilmemiştir. 3B maddesi en fazla gram pozitif bir bakteri olan Bacillus megaterium DSM 32 üzerinde etki göstermiş̧ir ve inhibisyon çap1 $20 \mathrm{~mm}$ olarak ölçülmüştür. En az inhibisyon çap1 ise Salmonella enterica ATTC 13311 üzerinde $8 \mathrm{~mm}$ olarak tespit edilmiştir. 3C maddesi uygulandığında en fazla etkinin Staphylococcus aureus 6538P üzerinde olduğu ölçülmüş olup inhibisyon çapı zon çap1 $12 \mathrm{~mm}$ olarak belirlenmiştir. En az etki $4 \mathrm{~mm}$ inhibisyon çapı ile Pseudomonas aeruginosa DSM 50070 üzerinde ölçülmüştür. 4B maddesi ile yapılan deney sonuçlarına göre en fazla etki Brevibacillus brevis ve Staphylococcus aureus 6538P suşlarında görülmüştür ve bu bakterilerin her ikisi de gram pozitif bakteridir ve inhibisyon zon çapları $10 \mathrm{~mm}$ olarak ölçülmüştür. En az etkinin ise gram negatif bakterileri olan Enterobacter aerogenes CCM 2531 ve Proteus vulgaris FMC II suşlarında görülmüştür, inhibisyon zon çapları her ikisinde de $4 \mathrm{~mm}$ olarak ölçülmüştür. Bununla beraber Proteus vulgaris suşu üzerine ise herhangi bir inhibisyon etkisi olmamıştır. Disk difüzyon yöntemi sonuçlarına göre $4 \mathrm{C}$ maddesi, gram pozitifler üzerinde 6-8 $\mathrm{mm}$ arasında; gram negatifler üzerinde ise $2-5 \mathrm{~mm}$ arasında inhibisyon zonları oluşturarak antimikrobiyal aktivite gösterdiği tespit edilmiştir. Gram negatifler üzerinde ise $2-5 \mathrm{~mm}$ arasında inhibisyon zonları oluşturmuştur. Ayrıca en fazla etki Brevibacillus brevis, Bacillus megaterium DSM 32 ve Listeria monocytogenes NCTC 5348 suşlarında olup zon çaplar1 8 mm olarak, en az etki ise gram negatif bakteri olan Pseudomonas aeruginosa DSM 50070 suşunda olup zon çap 2 mm olarak ölçülmüştür.

1,2,4-triazol3-benzilsulfanil türevleri ile yapılan in vitro çalışmalarda Mycobacterium tuberculosis, M. avium, ve M. kansasii üzerinde antibakteriyel özellikleri olduğu yayınlanmıştır [27]. Başka bir çalışmada bazı sentezlenmiş 1,2,4-triazole türevlerinin gram negatif bakteriler ( $S$. aureus ve $B$. subtilis) ve gram pozitif bakteriler ( $P$. aeruginosa ve $E$. coli) üzerinde etkinlikleri olumlu sonuçlar alınmıştır [28]. Çalışmamızda yapılan antibakteriyel ölçümlerde genel olarak tüm maddeler gram pozitifler üzerinde daha etkili olduğu tespit edilmiş, $3 \mathrm{~B}$ ve $3 \mathrm{C}$ maddeleriyle gerçekleştirilen disk difüzyon testinde en yüksek zon çapları ölçülmüştür. 
Tablo1. Maddelerin farklı bakteri türlerine karşı disk difuzyon duyarlılık testi sonuçları

\begin{tabular}{|c|c|c|c|c|c|c|}
\hline & & \multicolumn{5}{|c|}{ Maddelerin zon çapları (mm) } \\
\hline \multicolumn{2}{|r|}{ Mikroorganizma } & 2 & $\mathbf{3 b}$ & $3 c$ & 4b & $4 c$ \\
\hline \multirow{7}{*}{$\begin{array}{l}\text { Gram } \\
\text { pozitif } \\
\text { bakteriler }\end{array}$} & Bacillus subtilis ATCC 6337 & 8 & 13 & 11 & 9 & 7 \\
\hline & Brevibacillus brevis & 6 & 15 & 12 & 10 & 8 \\
\hline & Bacillus megaterium DSM 32 & 8 & 20 & 11 & 9 & 8 \\
\hline & Bacillus subtilis IM 622 & 7 & 14 & 9 & 8 & 7 \\
\hline & Bacillus cereus EMC 19 & 6 & 16 & 10 & 9 & 7 \\
\hline & Staphylococcus aureus $6538 P$ & 7 & 17 & 13 & 10 & 6 \\
\hline & Listeria monocytogenes NCTC 5348 & 9 & 14 & 11 & 9 & 8 \\
\hline \multirow{10}{*}{$\begin{array}{l}\text { Gram } \\
\text { negatif } \\
\text { bakteriler }\end{array}$} & Salmonella typhimurium NRRLE 4413 & 3 & 12 & 9 & 5 & 4 \\
\hline & Pseudomanas fluorescens & 4 & 9 & 8 & 6 & 5 \\
\hline & Enterobacter aerogenes CCM 2531 & 3 & 12 & 8 & 4 & 3 \\
\hline & Klebsiella pneumoniae EMCS & 3 & 11 & 5 & 5 & 4 \\
\hline & Escherichia coli ATCC 25922 & 2 & 11 & 6 & 6 & 5 \\
\hline & Proteus vulgaris FMC II & 1 & 12 & 6 & 4 & 3 \\
\hline & Pseudomonas aeruginosa DSM 50070 & 1 & 9 & 4 & 5 & 2 \\
\hline & Proteus vulgaris & 0 & 10 & 6 & 0 & 3 \\
\hline & Salmonella enterica ATTC 13311 & 2 & 8 & 7 & 6 & 3 \\
\hline & DMSO & 0 & 0 & 0 & 0 & 0 \\
\hline
\end{tabular}

\section{Sonuç ve Öneriler}

Günümüzde en çok ölümle sonuçlanan hastalıklardan biri olan kanserin tedavisi için de bugüne kadar değişik yöntemler geliştirilmiş ve bu bağlamda değişik yapılara sahip bileşikler tedavi edilme amaçlarıyla sentez edilmiştir. Yine pek çok bileşiğin antibakteriyel özellikleri tıbbi alanda kullanımlar için araştırılmaktadır. Bu çalışmada kullanılan maddelerin daha önceki çalışmada gösterildiği üzere yüksek antioksidan kapasiteye sahip olmaları aynı zamanda antikanser, antimikrobiyal ve apoptotik etkilerinin tespiti kanser başta olmak üzere pek çok hastalığın tedavisinde kullanılabileceğini ortaya koymaktadır. Ayrıca in vivo analizler ile daha detaylı araştırmalar yapılması ön görülmektedir.

\section{Teșekkür}

$\mathrm{Bu}$ araştırma Bingöl Üniversitesi BÜBAP (proje numaras1 BAP-712-297-2015) tarafindan desteklenmiştir. Kimyasal bileşiklerin teminini sağlayan Prof. Dr. Ahmet ÇETíN'e ve bakteriyel suşların teminini sağlayan Doç. Dr. Fethi Ahmet ÖZDEMİR'e teşekkür ederiz.

\section{Yazarların Katkısı}

Çalışmada yazarlar eşit oranda katkı sunmuştur.

\section{Çıkar Çatışması Beyanı}

Yazarlar arasında herhangi bir çıkar çatışması bulunmamaktadır.

\section{Araştırma ve Yayın Etiği Beyanı}

Yapılan çalışmada, araştırma ve yayın etiğine uyulmuştur.

\section{Kaynaklar}

[1] Bray F., Ferlay J., Soerjomataram I., Siegel R.L., Torre L.A., Jemal A. 2018. Global Cancer Statistics 2018 GLOBOCAN Estimates of Incidence and Mortality Worldwide for 36 Cancers in 185 Countries. CA: Cancer Journal of Clinicians, 68: 394-424. 
[2] Bostwick D.G., Burke H.B., Djakiew D., Euling S., Ho S.M., Landolph J., Morrison H., Sonawane B., Shifflett T., Waters D.J., Timms B. 2004. Human prostate cancer risk factors. Cancer, 101 (10): 2371-2490.

[3] Jemal A., Murray T., Ward E., Samuels A., Tiwari R.C., Ghafoor A., Thun M.J. 2005. Cancer statistics, 2005. CA: Cancer Journal for Clinicians, 55: 10-30.

[4] Banerjee S., Ganguly S., Sen K.K. 2013. A Review on 1, 2, 4 -Triazoles. Journal of Advanced Pharmacy Education \& Research, 3 (3): 102-115.

[5] Bulut N., Kocyigit U.M., Gecibesler I.H., Dastan T., Karci H., Taslimi P., Dastan S.D., Gulcin I., Cetin A. 2018. Synthesis of some novel pyridine compounds containing bis-1,2,4triazole/thiosemicarbazidemoiety and investigation of their antioxidant properties, carbonic anhydrase, and acetylcholinesterase enzymes inhibition profiles. Journal of Biochemical Molecular Toxicology, DOI: 10.1002/jbt.22006, 1-10.

[6] Mothes-Wagner U., Reitze H.K., Seitz K.A. 1990. Environmental actions of agrochemicals 1. Side-effects of the herbicide 3-amino-1,2,4-triazole on a laboratory acarine/host-plant interaction (Tetranychus urticae/Phaseolus vulgaris) as revealed by electron microscopy. Experimantal and Applied Acarology, 8 (2): 27-40.

[7] Taj T., Kamble R.R., Gireesh T., Badami B.V. 2011. An expendeditious green synthesis of bases and azetidinones derivatised with 1,2,4-trizoles. Journal of Chemical Sciences, 123 (5): 657-666.

[8] Hassan F.A., Younus K.W. 2012. Biological evaluation of some azole derivatives in cooling fluids (Lubricant Oils). Research Journal of Biological Sciences, 7 (1): 48-51.

[9] Abdullah H.M., Jassim I.K., Safi M.N. 2012. Synthesis and characterization of new heterocyclic compounds with studying 1ts biological activity. Kerbala Journal of Pharmaceutical Sciences, 4: 119-135.

[10] Jabar A., Al-Mufrgeiy S.S. 2012. Synyhesis and antibacterial activities of new 3-amino-2-methylquinazolin-4(3h)-one derivatives. American Journal of Chemistry, 2 (3): 150-156.

[11] Pardeshi S.P., Patil S.V., Patil R., Bobade V.D. 2014. Synthesis and antimicrobial activities of some 1,2,4- triazolo[3,4-b][1,3,4]thiadiazoles and 1,2,4-triazolo [3,4-b][1,3,4]thiadiazines bearing bistrifluoromethyl phenyl moiety. Journal of Chemical Pharmaceutical Research, 6 (4): 675-681.

[12] Bekircan O., Menteşe E., Ülker S., Kucuk C. 2014. synthesis of some new 1,2,4-triazole derivatives starting from 3-(4-chlorophenyl)-5-(4-methoxybenzyl)-4h-1,2,4-triazol with antilipase and anti-urease activities. Archiv derPharmazie Chemistry Life Sciences, 347: 387-397.

[13] Sripriya1 S., Subha C., Selvaraj A. 2013. The inhibition chemistry of 2-amino, 5-phenyl 1, 3, 4triazole for aluminium in hydrochloric acid solution. IOSR-Journal of Applied Chemistry, 6 (2): 25-29.

[14] Sengupta A.K., Garg M. 1988. Studies on potential pestisides-part xiv synthesis and biological activities of some new thiosemicarbazide and triazole derivatives. Definition of Science, 31 (2): 91-96.

[15] Er J.C., Tang M.K., Chia C.G., Liew H., Vendrell M., Chang Y.T. 2014. Megastockes BODIPYtriazoles as environmentally sensitive turn-on fluorescent dyes. Journal of Chemical Sciences, 4: 2168-2176.

[16] Bulut V.N., Duran C., Gundogdu A., Soylak M., Yildirim N., Tufekci M. 2010. A triazole derivatives as a new acid-base indicator. Bulletin of the Chemical Society Ethiopia, 24 (3): $457-$ 460.

[17] Cassani S., Kovarich S., Roy P.P., Van der Wal L., Gramatica P. 2013. Daphnia and fish toxicity of (benzo) triazoles: validated qsar models, and interspecies quantitative activity-activity modeling. Journal of Hazardous Materials, 258-259: 50-60.

[18] Kisgen J. 2015. Lippincott Illustrated Reviews: Pharmacology $6^{\text {th }}$ edition, Wolters Kluwer, Hong Kong.

[19] Karcı H. 2013. Yeni bis-1,2,4-triazol türevlerinin antioksidan aktivitelerinin incelenmesi. Yüksek Lisans Tezi, Bingöl Üniversitesi, Fen Bilimleri Enstitüsü, Bingöl.

[20] Benedict R.G., Brady L.R. 1972. Antimicrobial activity of mushroom metabolites. Journal of Pharmaceutical Sciences, 61 (11): 1820-1822.

[21] Biemer J.J. 1973. Antimicrobial susceptibility testing by the kirby-bauer disc diffusion method. Annals of Clinical Laboratory Science, 3 (2): 135-140. 
[22] Subrahmanya B.K., Boja P., Jagadeesh P.D., Prashantha N., Shivarama H.B. 2009. Synthesis and antitumor activity studies of some new fused 1,2,4-triazole derivatives carrying 2,4-dichloro-5fluorophenyl moiety. European Journal of Medicinal Chemistry, 44: 5066-5070.

[23] Al-Soud Y.A., Al-Dweri M.N., Al-Masoudi N.A. 2004. Synthesis, antitumor and antiviral properties of some 1,2,4-triazole derivatives. Farmaco, 59 (10): 775-783.

[24] Demirbas N., Ugurluoglu R., Demirbas A. 2002. Synthesis of 3-Alkyl(Aryl)-4-alkylidenamino4,5-dihydro- 1H-1,2,4-triazol-5-ones and 3-Alkyl-4-alkylamino-4,5-dihydro-1H-1,2,4-triazol-5ones as Antitumor Agents. Bioorganic and Medicinal Chemistry, 10: 3717-3723.

[25] Sztanke K., Tuzimski T., Rzymowska J., Pasternak K., Kandefer-Szerszen M. 2008. Synthesis, determination of the lipophilicity, anticancer and antimicrobial properties of some fused 1,2,4triazole derivatives. European Journal of Medicinal Chemistry, 43: 404-409.

[26] Porter A.G., Jänicke R.U. 1999. Emerging roles of caspase-3 in apoptosis. Cell Death and Differentiation, 6: 99-145.

[27] Klimešová V., Zahajská L., Waisser K., Kaustová J., Möllman U. 2004. Synthesis and antimycobacterial activity of 1,2,4-triazole 3-benzylsulfanyl derivatives. Farmaco, 59 (4): 279288.

[28] Jain R.K., Mishra V.K., Kashaw V. 2017. Synthesis and antimicrobial activity of some new 1,2,4trizoles. Asian Journal of Chemistry, 29 (6):1317-1322. 